\title{
EVALUATION OF ELECTRON-BEAM COLD HEARTH REFINING (EBCHR) OF VIRGIN AND REVERT IN738LC
}

\author{
P.N. Quested*, M. McLean* and M.R. Winstone ${ }^{\dagger}$ \\ *Division of Materials Applications, National Physical Laboratory, \\ Teddington, Middx, TW11 OLW, UK \\ $\dagger$ Propulsion Department, Royal Aerospace Establishment, \\ Pyestock, Farnborough, Hants. UK
}

\begin{abstract}
Summary
A collaborative programme involving $12 \mathrm{UK}$ industrial and research organisations $\#$ has assessed the effects of EBCHR on the chemistry, microstructure, casting performance and mechanical behaviour of both virgin and revert casts of IN738LC. Small differences in chemistry and microstructure of the alloy variants do not significantly influence either the casting performance or the mechanical behaviour. Consequently, the work provides no commercial incentive for the use of EBCHR on cast superalloys of the purity levels considered in this investigation. Acceptable castings were obtained from all four bar stocks, the most expensive of which was about ten times the cost of the cheapest.
\end{abstract}

\# AE Turbine Components Ltd

Cameron Iron Works Ltd

Glossop Superalloys Ltd

INCO Alloys Ltd

INCO Engineered Products Ltd

National Physical Laboratory

Rolls-Royce plc - Aero and Industrial/Marine Divisions

Ross and Catherall Ltd

Royal Aerospace Establishment

Ruston Gas Turbines Ltd

TI Reynolds Ltd

Vickers Precision Components Ltd

Superalloys 1988

Edited by S. Reichman, D.N. Duhl,

G. Maurer, S. Antolovich and C. Lund

The Metallurgical Society, 1988 
It is well established that the mechanical behaviour of superalloys can be profoundly influenced by the presence of traces of various residual solutes and contaminating gases $(1)$ and that the occurrence of porosity in cast superalloys can be associated with increases in nitrogen content $(2)$. The quality of VIM bar stock for investment casting is an important factor in optimising the service performance of cast components. It has been claimed that EBCHR of VIM bar-stock can lead to significant improvements in the yield of difficult-to-cast parts, particularly for revert superalloys $(3,4)$. However, there is little systematic evidence of the effects of EBCHR on chemistry, microstructure, castability and mechanical performance (5). The present investigation considers the use of EBCHR secondary melting to improve the purity and cleanliness of a superalloy of two quite different levels of starting purity.

a) Examination of the trends in the fall of stress rupture life and rupture ductility with increasing trace element concentration shows that the relative effects are greatest at the lowest concentrations $(1)$. This suggests that significant improvements in mechanical performance may result from reducing the concentrations of detrimental trace elements to even lower levels than can be achieved in virgin alloy melts. Consequently one objective was to examine whether a superalloy, prepared by EBCHR of a virgin cast prepared to the highest VIM specification, had any advantages over existing cast superalloys.

b) The main detrimental effects of reverting nickel-base superalloys appear to be associated with accumulations of nitrogen, oxygen, and silicon originating from melt/mould and melt/environment interactions. These can lead to a variety of problems that limit the use of revert alloys for critical components - eg. microporosity, hot tearing, reduced fatigue resistance, decreased ductility, increased scatter in rupture life, etc. It is believed that these phenomena are consequences of inclusions, such as $\mathrm{TiN}$ and $\mathrm{Al}_{2} \mathrm{O}_{3}$, that remain stable within the melt and that can be removed by sophisticated EBCHR processing. A second objective of the programme was to evaluate EBCHR when applied to a $100 \%$ revert cast prepared using current commercial practice.

The work was carried out on the alloy IN738LC which is extensively used in industrial and marine gas turbines. The programme was organised by the UK Superalloy Panel and the characterisation of the various alloy variants, which was shared by the participating organisations, included duplication and cross-referencing to minimise systematic errors in various mesurements. The plan of the study is summarised in the flow diagram shown in Figure 1.

\section{$\underline{\text { Alloy Production }}$}

The two initial bar-stocks for the programme were produced in the UK by vacuum induction melting (VIM) using the best current industrial practice on different types and grades of starting materials.

a) A high purity virgin cast of IN738LC, weighing approximately $600 \mathrm{~kg}$, was prepared using the highest purity raw materials that could be obtained consistent with economic requirements. Except for zirconium, only primary raw materials were used. The base charge in the furnace, consisting of $\mathrm{Ni}, \mathrm{Cr}, \mathrm{Co}, \mathrm{Ta}, \mathrm{Mo}, \mathrm{W}$ and $\mathrm{Nb}$, was melted in a high alumina crucible while the more reactive constituents ( $\mathrm{Al}, \mathrm{Ti}, \mathrm{B}$, $\mathrm{Zr}, \mathrm{Mg}$ ) were added late in the process. The charge was cast into $75 \mathrm{~mm}$ diameter steel moulds using tea-pot pouring and passing the metal through two tundishes in order to minimise the transport of inclusions from the melt. The total time for the complete process of 14 hours included an extended melt-hold period to ensure the evaporation of metalloids.

b) A revert cast weighing $500 \mathrm{~kg}$ was prepared from cleaned scrap of known pedigree produced during investment casting in a single foundry. A commercial manufacturing 
route was followed using a crucible of spinel dry-rammed refractory powder $(70 \%$ $\mathrm{Al}_{2} \mathrm{O}_{3}, 30 \% \mathrm{MgO}$ nominal). The alloy was teemed into $75 \mathrm{~mm}$ diameter steel moulds through a refractory tundish incorporating an alumina reticulated foam filter and a head box.

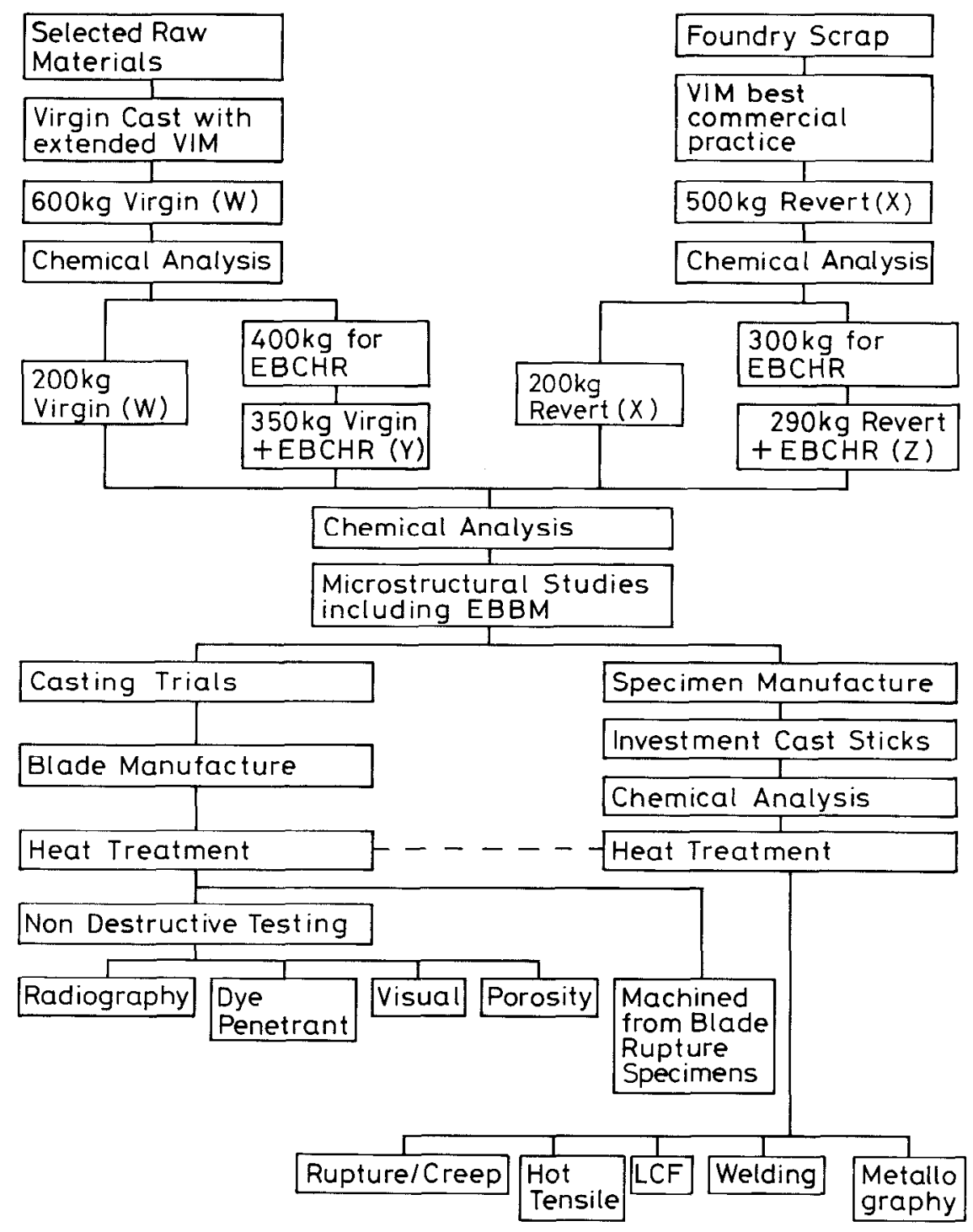

Figure 1 Flow Diagram of Technical Programme

About $400 \mathrm{~kg}$ of the virgin alloy (W) and $350 \mathrm{~kg}$ of the revert alloy (X) were reprocessed by EBCHR by a specialist U.S. subcontractor. The EBCHR process, which has been described previously(6), used a single gun with a maximum available power of $250 \mathrm{~kW}$ at $30 \mathrm{kV}$ and the electron beam was programmed to melt the ingot, sweep the melt contained in a water-cooled copper hearth in order to isolate any floating inclusions and control the solidification of the ingot. No attempt was made to adjust the alloy compositions during EBCHR to compensate for losses of the more volatile constituents such as chromium because of the dangers of introducing associated gaseous contaminants. In order to conserve material during EBCHR, the virgin alloy (W) was remelted first to produce a refined alloy $(Y)$. The skull formed on the water-cooled hearth by the virgin alloy was retained and used in processing the revert VIM alloy (X) into the refined version ( $Z$ ). It was estimated that the first $50 \mathrm{~kg}$ of alloy $\mathrm{Z}$ would be mixed with some of the alloy $W$ skull; this material was not used in subsequent characterisation. 


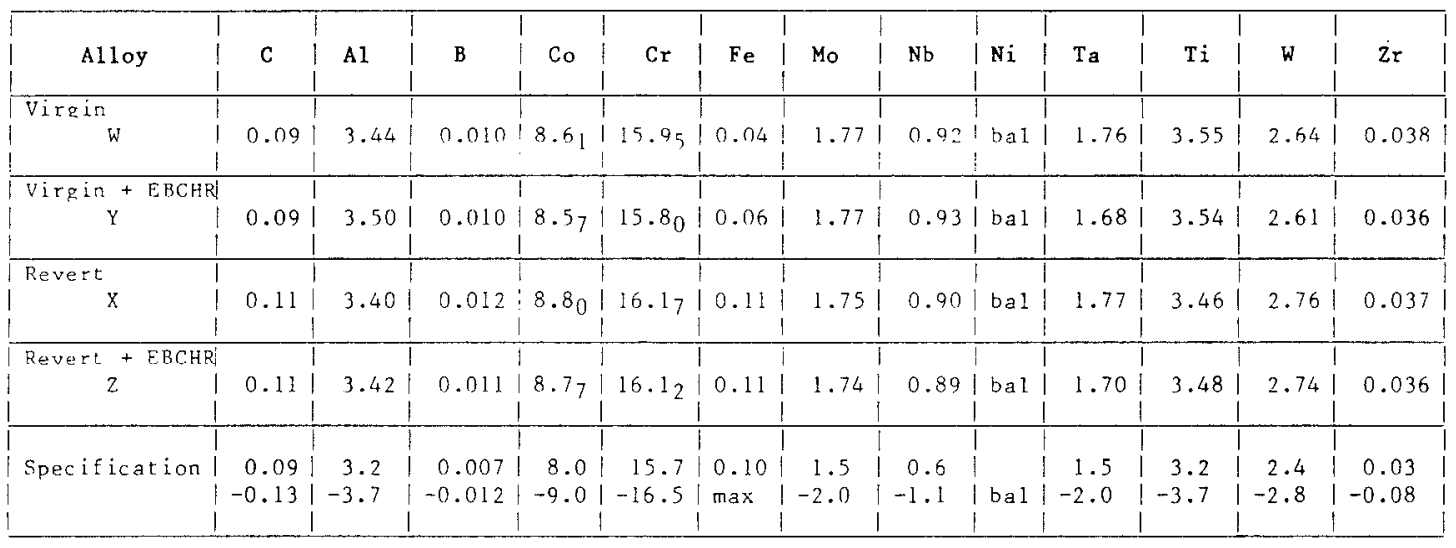

The following minor constituents were analysed and found to be below the specified levels. $\mathrm{Si}, \mathrm{Mn}, \mathrm{P}, \mathrm{S}, \mathrm{Ag}, \mathrm{As}, \mathrm{Bi}, \mathrm{Ca}, \mathrm{Cd}, \mathrm{Cu}, \mathrm{Ga}, \mathrm{In}, \mathrm{Hf}, \mathrm{Mg}, \mathrm{Pb}, \mathrm{Sb}, \mathrm{Se}, \mathrm{Sn}, \mathrm{Te}, \mathrm{T} 1, \mathrm{~V}, \mathrm{Zn}$.

TABLE 2: NITROGEN AND OXYGEN ANALYSES OF THE FOUR ALLOY VARIANTS

\begin{tabular}{|c|c|c|c|c|c|c|}
\hline \multirow{2}{*}{ HEAT } & \multicolumn{3}{|c|}{ NITROGEN } & \multicolumn{3}{|c|}{ OXYGEN } \\
\hline & MEAN & RANGE & NUMBER & MEAN & RANGE & NUMEER \\
\hline virgin $W$ & 6 & $5.6-6.9$ & 5 & 12 & $8.3-14.0$ & 5 \\
\hline Virgin + EBCHR & 6 & $4.9-7.7$ & 10 & 6 & $3.3-8.5$ & 10 \\
\hline Revert $X$ & 30 & $28.2-30.5$ & 10 & 12 & $9.6-17.3$ & 10 \\
\hline Revert $+\mathrm{EBCHR}$ & 27 & $24.7,-28.8$ & 10 & 7 & $3.9-11.5$ & 10 \\
\hline
\end{tabular}

Tapered test bars of two different sizes were prepared from all four alloy variants by an identical investment casting route. The metal was super-heated in vacuum to $1560^{\circ} \mathrm{C}$, the temperature stabilised and the charge poured at a temperature of $1530^{\circ} \mathrm{C}$ into ceramic moulds. Standard release checks which included visual, $X$-ray and fluid penetrant cxamination and porosity measurements were carried out.

The bar castings, together with blades prepared for the casting evaluation, from all four alloys were heat treated at the same time. The standard commercial heat treatment for IN738LC was used; viz. a solution treatment of $2 \mathrm{~h}$ at $1120^{\circ} \mathrm{C}$ in vacuum followed by an argon fan quench and a precipitation treatment of 24 hours at $845^{\circ} \mathrm{C}$.

\section{Characterisation}

\section{a) Chemical analysis}

The chemical analyses for all four alloys are compared in Tables 1 and 2 with the original alloy specification. The values quoted in Table 1 represent the findings of 7 analysts from the collaborating organisations for the major constituents in the four bar-stocks. However, the results for oxygen and nitrogen obtained by the inert gas fusion method showed a wide scatter. This inconsistency has led to an independent investigation into the gas fusion technique aimed at producing reference standards and a UK protocol for gas analysis of superalloys. In subsequent discussion the figures quoted are for gas analysis from the single laboratory that performed the greatest number of analyses showing little scatter and which were generally consistent with the results from other laboratories (Table 2). 
There are small differences in the major element compositions of the VIM virgin and revert alloys the latter having higher $\mathrm{Cr}, \mathrm{Co}, \mathrm{Fe}$ and $\mathrm{W}$ and lower $\mathrm{Ti}$. However, both fall within the specified range for IN738LC adopted for this programme. The nitrogen level in the revert alloy $X$ at $30 \mathrm{ppm}$ was significantly higher than the $6 \mathrm{ppm}$ measured in the virgin material (W). The oxygen contents of alloys $\mathrm{W}$ and $\mathrm{X}$ were both $12 \mathrm{ppm}$.

After EBCHR there was a marginal reduction in nitrogen content for the revert heat (30 ppm for $X$ to $27 \mathrm{ppm}$ for $\mathrm{Z}$ ) but a significant change in oxygen content for both virgin and revert alloys. Changes in major element concentrations after EBCHR were small the largest effect being a reduction in $\mathrm{Cr}$. However, the changes detected were close to the limits of accuracy of X-ray fluorescence spectrometry and EBCHR had no significant effect on the major alloy chemistry. No effects on the concentrations of volatile trace elements were noted the values being close to the reporting limits.

No significant changes in chemistry between the bar-stock and cast forms of the alloys were detected.

\section{b) $\underline{\text { Microstructure }}$}

Polished sections of both the bar-stock and the cast bars were examined by optical microscopy; both etching with Marbles reagent and use of interference film microscopy enhanced contrast of various features. Microporosity was determined by different participants in the programme using established in-house procedures utilising quantitative metallography.

Examination of the bar-stock showed the carbides in the revert alloy $X$ to be small and blocky rather than having the acicular,or mixed blocky/acicular, form characteristic of the other alloy variants (Figure 2). The detailed structure of the carbides in the revert alloy was complex generally exhibiting oxide and nitride centres which were not readily apparent in the other materials. Differences in the carbide shape and structure were less pronounced in the castings than in the bar stock. However, the castings produced from revert alloy $X$ generally had a more equiaxed grain structure than those prepared from alloys $\mathrm{W}, \mathrm{Y}$ and $\mathrm{Z}$ (Figure 3 ).

The highest levels of porosity in the bar castings occurred in the revert material (X) although this was at a very low level. There was negligible porosity in castings produced from the other three alloys.

\section{c) Electron beam button melting}

Samples of each bar-stock weighing approximately $700 \mathrm{gm}$ were electron beam button melted (EBBM) to provide a measure of the total inclusion content. The alloy cleanliness was assessed by measuring the extent of the inclusion-rich raft on the button surface. Detailed examination of inclusions by scanning electron microscopy using back-scattered electron images, cathodoluminescence and X-ray mapping were also carried out. A full account of this phase of the characterisation has been published previously $(6)$ and only the most important aspects are reported below.

Typical cap areas for the four alloys are shown in Figure 4. There was a remarkable consistency in the results obtained using a standard cycle in a single machine for runs carried out over several months. There is a clear reduction in cap size between the revert alloy $X$ and EBCHR version $Z$. Alloy $X$ exhibits both a rough central raft of oxide particles ( $100 \mu \mathrm{m}$ diameter) and a larger surrounding region of $(\sim 5 \mu \mathrm{m}$ diameter $)$ TiN inclusions in a nickel matrix. The oxide zone is much smaller in alloy $Z$ which still retains TiN cubes. In the virgin alloy $W$ the cap contained oxides but few nitrides while the EBCHR version $Y$ only exhibited carbides although the cap was larger than that obtained for the original VIM material. Chakravorty et al(7) discuss the differences in EBBM analysis associated with different machine geometries. 


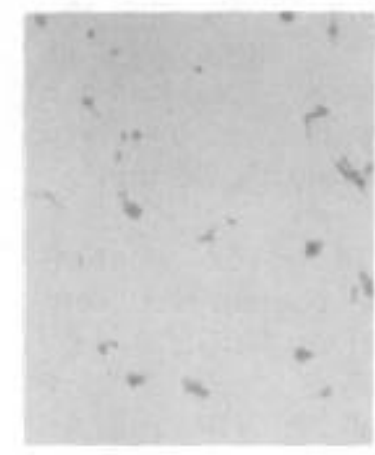

Virgin

Figure 2 Micrographs showing carbide morphology in the tour bar stocks

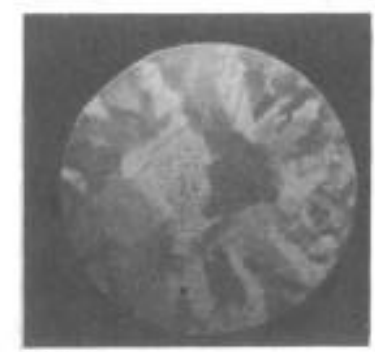

Virgin

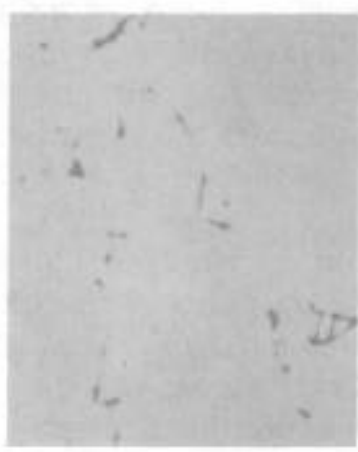

Virgin + EBCHR

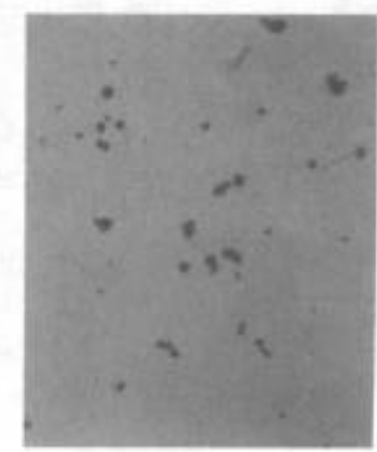

Revert

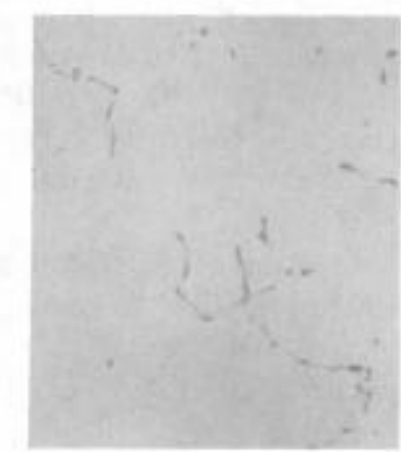

Revert + EBCHR

$40 \mu \mathrm{m}$

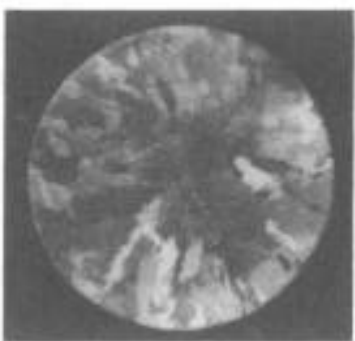

Virgin + EACHR

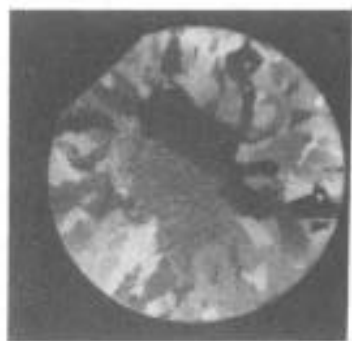

Revert

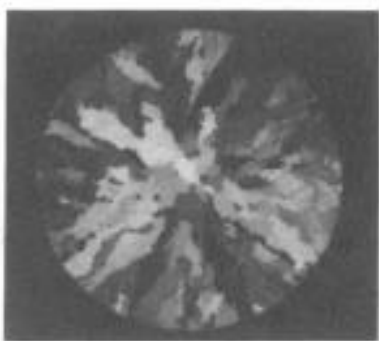

Revert + EBCHR

$4 \mathrm{~mm}$,

Figure 3 Mucrographs of tipical grain motphoiogues on the fransvers: अanions ot cast Dar

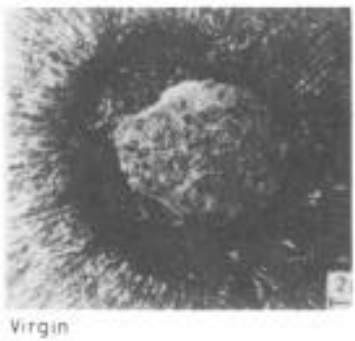

Virgin

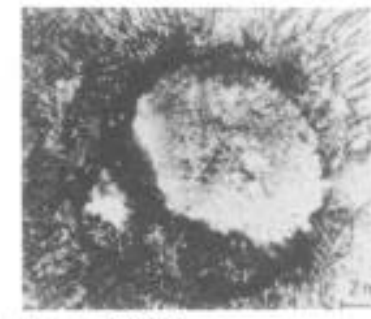

Virain + EBCHR

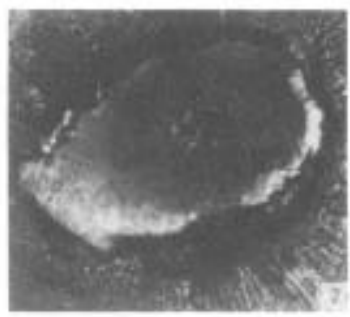

Pevert

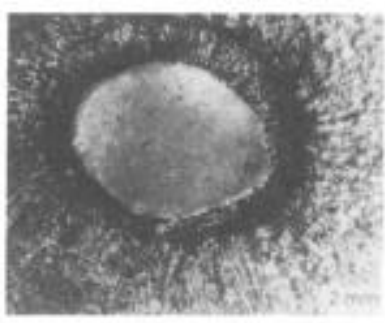

Revert + EBCHB

Figure 4 Micrographs of inclusion rich cops on buttons prepared by EBBM of the tour bar stocks

\section{Mechanical Tests}

The mechanical test programme was shared by 7 of the collaborating laboratories and included a series of callibration tests to ensure compatability of results. In all cases the inter-laboratory variation was within the expected experimental scatter.

\section{Tensile Tests}

Tensile specimens from each alloy were tested over the temperature range $20^{\circ} \mathrm{C}$ to $900^{\circ} \mathrm{C}$. Tests were concentrated around $700-800^{\circ} \mathrm{C}$ to identify any ductility trough or peak in strength. Figure 5 summarises the results. Most of the data points are the average of 2 tests. A sharp peak in the proof stress and tensile strength occurred at $750^{\circ} \mathrm{C}$ and above this temperature the strengths of all the alloys were similar. However at lower temperatures there were some small, but significant, differences. The virgin alloy W had a consistently higher proof stress, while alloy $\mathrm{Z}$ had a low proof stress. The revert alloy $\mathrm{X}$ had a lower tensile strength than the other alloys. It was noted that EBCHR increased the low temperature ductility of both alloys. This was most noticeable for the revert + $\mathrm{EBCHR}$ alloy $\mathbf{Z}$ and resulted in a significant increase in tensile strength. 


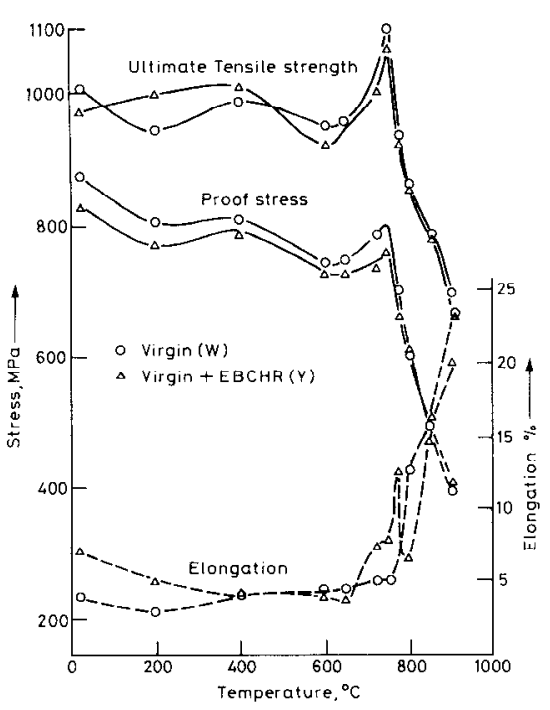

Figure $5 a$ Tensile data for cast bars prepared from Virgin and Virgin + EBCHR alloys

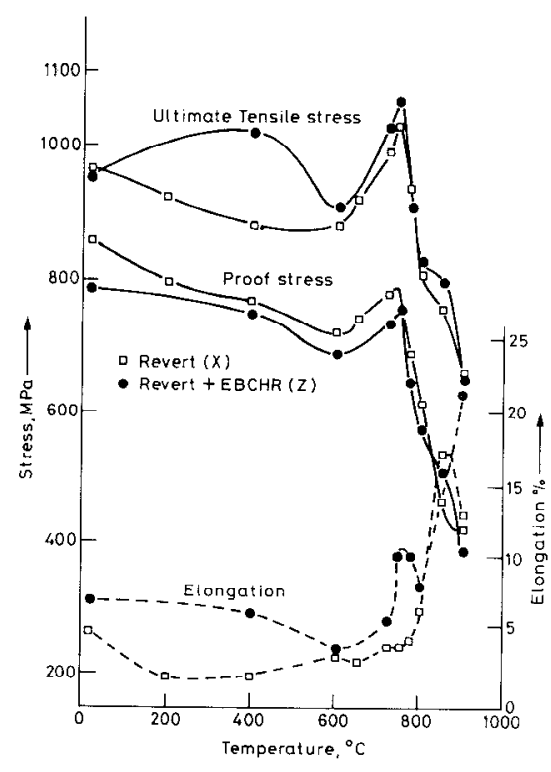

Figure $5 b$ Tensile data for cast bars prepared from

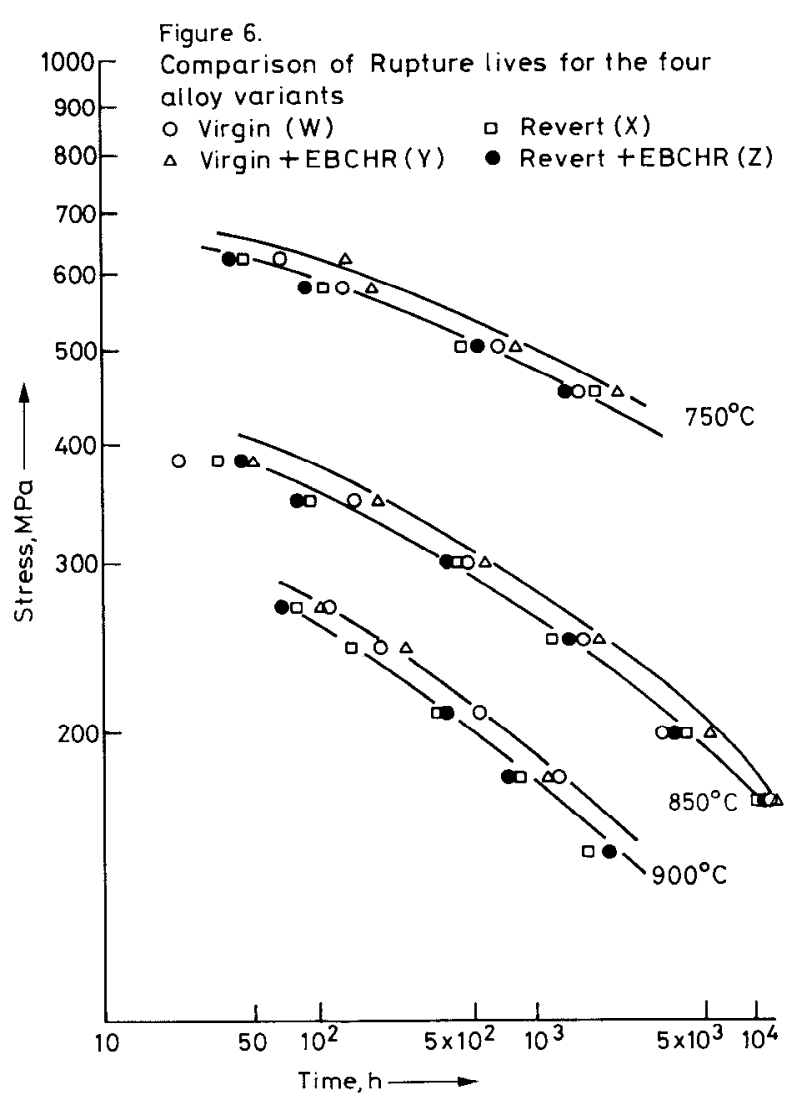

\section{Rupture Tests}

The results of stress rupture tests at $750^{\circ} \mathrm{C}, 850^{\circ} \mathrm{C}$ and $900^{\circ} \mathrm{C}$ with stresses chosen to give rupture lives in the range 50-10000 hours are plotted in Figure 6. All the data are grouped within a tight scatter band and it is not possible to identify a clear advantage for any one material. However, there is a difference between the virgin and revert alloys. Both virgin alloys ( $W$ and $Y$ ) tend to lie at the top of the scatter band, with the revert alloys ( $\mathrm{X}$ and $\mathrm{Z}$ ) towards the bottom. No advantage of EBCHR can be identified: the ductility increase noted in the tensile test data was not observed under creep conditions. 

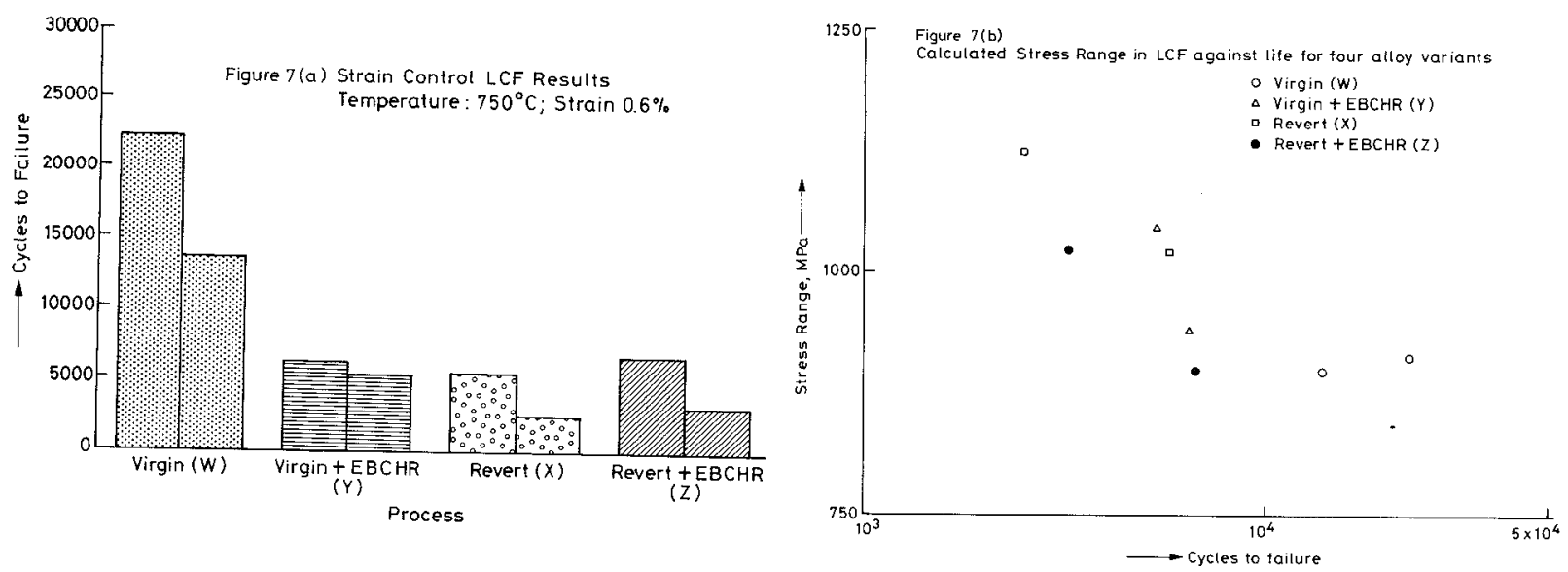

Low Cycle Fatigue Tests

Duplicate strain control fatigue tests were performed on each alloy at $750^{\circ} \mathrm{C}$ using a strain range of $\pm 0.3 \%$ and a frequency of $1 \mathrm{~Hz}$. The fatigue life of the virgin alloy $W$ was more than twice those of the other materials, the revert alloy $X$ falling slightly below the EBCHR materials ( $\mathrm{Y}$ and $\mathrm{Z}$ ). This result must be treated with caution because it was also observed that there was a considerable variation in elastic modulus between test pieces. For example, the room temperature elastic modulus varied from $189-238 \mathrm{GPa}$. A similar variation in elastic modulus was seen in the tensile tests and is believed to be the result of crystallographic texture aassociated with different grain morphologies (Figure 3) and to be compounded by a small test piece cross-section and large grain size. To remove the dependence on modulus, Figure 7 plots the low cycle fatigue data in terms of stress range. The high elastic modulus specimens have a much higher stress range, and a shorter life. There is a suggestion that the virgin alloy $W$ has the best fatigue properties, while the revert $+E B C H R$ alloy $Z$ has the lowest life. However, the differences are quite small.

The results of a second series of stress controlled tests, carried out in a second laboratory using a different specimen geometry and testing machine show a different ranking of materials, suggesting that EBCHR increases the LCF performance of both virgin and revert materials.

\section{Casting trials}

The four alloys were used to cast 80 commercial turbine blades which are known to have a difficult-to-cast geometry. The alloy charges were melted in a disposable silica-lined crucible backed by a mullite/sillimanite part. The melt pouring temperature was $1490^{\circ} \mathrm{C}$. The foundry reported a higher dross level for the revert alloy $X$ than for the other materials. The blades were heat treated and examined for any differences in the soundness of the castings using the manufacturers normal inspection procedures.

The results of radiographic, dye penetrant and visual inspection failed to show any significant difference in the quality of blades manufactured from the four alloy variants. Figure 8 shows the normalised porosity-based measurements from a total of 44 blades for the four alloys taken in each case from 12 sections comprising four from the root, five from the aerofoil and three from the shroud. The mean values for blades manufactured from typical revert and virgin heats are included for reference. All the blades cast from the four alloys under consideration would be accepted on the basis of the manufacturers criteria for microporosity levels. By contrast, a proportion of the blades from the comparison production revert cast would be rejected. Surprisingly, the lowest microporosity levels were obtained from blade prepared from the revert alloy which is the opposite of the trend observed for the rod castings.

Little difference in the microstructures of the various blades was noted. Thus, similar carbide morphology, extent of $\gamma / \gamma^{\prime}$ eutectic and $\gamma^{\prime}$ distribution were detected at equivalent sections of blades prepared from the different alloys. The largest microstructural 
differences were associated with different positions in the blade (eg. root, aerofoil, shroud) rather than with alloy and, consequently, can be considered to indicate sensitivity to cooling rate rather than composition.

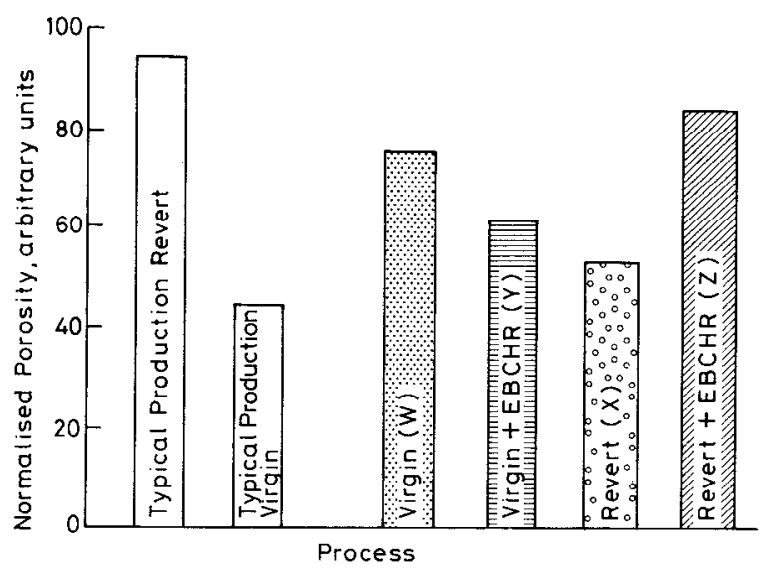

Figure 8 Mean Cumulative Porosity for samples cut from blades

Creep rupture specimens machined from the lower aerofoil sections of the blades were tested at $545 \mathrm{MPa} / 760^{\circ} \mathrm{C}$ and $230 \mathrm{MPa} / 930^{\circ} \mathrm{C}$. The company requirement is for minimum lives of 60 and $20 \mathrm{~h}$ and mean lives of 87 and $28 \mathrm{~h}$ for these two test conditions respectively. For the four alloys under consideration, all tests exceeded the specified average life by at least $80 \%$.

The welding characteristics of the cast versions of all four alloys was assessed using both the cast rod and blade materials. A range of welding procedures was considered, viz hard facing with Stellite 12 and lap-, butt- and patch-welds to Nimonic 75 using a range of filler alloys (INCO625, HASTELLOY X, NIMONIC 75). There was no evidence that EBCHR led to significant differences in welding characteristics. However, more crack-free welds were observed when using the revert casts $(X, Z)$ rather than the virgin materials $(\mathrm{W}, \mathrm{Y})$.

\section{Discussion and Conclusions}

The present study shows that EBCHR can result in small but significant changes in the composition and microstructure of both virgin and revert IN738LC. In particular, there is a reduction in the oxygen concentration, present in the form of oxides in the bar-stock, though surprisingly little change in nitrogen level; some changes in carbide morphology were also apparent. The bar-castings produced from these materials exhibit some changes in both the grain shape and the level of porosity. However, any changes in the mechanical properties of the bar-castings or the quality of blades produced from the four materials are marginal. The mechanical properties of all the alloys were near the top of the scatter band for commercial heats of IN738LC. Some minor differences between the various alloys were observed, but no clear benefit could be attributed to either the use of a carefully selected, high purity virgin heat or to the application of the EBCHR process. EBCHR did give a slight increase in the low temperature ductility and a modification of elastic modulus associated with a change in grain texture, but these factors are unlikely to be of engineering significance.

It is estimated that the cheapest bar-stock (alloy $\mathrm{X}$ ) which was prepared by remelting foundry scrap was about ten per cent of the cost of the most expensive (alloy $Y$ ) which was prepared from selected primary raw materials and electron beam cold hearth refined. Clearly, the present results can not justify this additional expenditure. The revert alloy considered in this study showed acceptable casting performance and mechanical behaviour. It is possible that a material with particularly poor casting characteristics would show greater benefits from EBCHR although the present study can not confirm this speculation. 
However, bearing in mind that the revert alloy considered here was prepared to current commercial practice using $100 \%$ scrap, it may be more cost-effective to select or blend appropriate scrap alloys rather than incur the expense of a secondary remelting process.

\section{Acknowledgement}

This programme was partially funded by the Metals Sectoral Advisory Committee of the Department of Trade and Industry.

\section{Copyright C Controller HMSO, London, 1988}

\section{$\underline{\text { References }}$}

1. M. McLean and A. Strang, Metals Technology 11, 454 (1984).

2. P.N. Quested, T.B. Gibbons and G.L.R. Durber, in "Materials Substitution and Recycling", AGARD Conference Proceedings 356, Paris, April 1984.

3. J.R. Mosher, in Proceedings of Conference "Electron Beam Melting and Refining State of Art", edited by R. Bakish, Reno, NV 1986. p.277.

4. M. Krehl and J.H.C. Lowe, in Proceedings of Conference" Electron Beam Melting and Refining - State of Art", edited by R. Bakish, Reno, NV (1986). p.286.

5. T.B. Gibbons, Proceedings of International Conference on Electron Beam Welding and Melting, Paris, p.545 (1970).

6. C d'A. Hunt, J.H.C. Lowe and S.K. Harrington in Proceedings of Conference "Electron Beam Melting and Refining - State of Art 1985" edited by R. Bakish, Reno, NV (1985) p.58.

7. S. Chakravorty, P.N. Quested and M. McLean, Proceedings of 1st European Conference of ASM International on "Advanced Materials and Processing", edited by T. Khan, Paris (in press). 